\title{
Exchange Rates, Productivity, Poverty and Inequality
}

\author{
by \\ Kenneth Clements and Yihui Lan \\ Economics Program \\ The University of Western Australia
}

\begin{abstract}
$\underline{\text { Abstract }}$
This paper analyses differences in the wealth of nations by comparing PPP-based cross-country incomes from the Penn Table with those derived from prevailing exchange rates. Using the Balassa (1964)-Samuelson (1964) productivity bias framework, we introduce the "international poverty line" and illustrate the implications for cross-county income inequality. We demonstrate that our results are not inconsistent with the previous literature when appropriately interpreted.
\end{abstract}




\section{Introduction}

One of the most important and controversial issues in the world economy is the measurement of wealth of nations. Some such measure is needed for making consistent comparisons of incomes across countries to identify those which have been more economically successful than others, to determine eligibility for foreign aid and concessional lending, to establish contributions to international agencies, and so on. This topic is highlighted in the following quotation of The Economist $\left(29^{\text {th }}\right.$ May 2004, p. 13): "How big is the world economy? That sounds likes a straightforward question. Simply to add up the size of all the world's national economies would seems to be the obvious way to answer it. But how that is done yields radically different results ... [W]hich method of measurement is used also affects more important matters: the global rate of growth, the relative size of economies, and the extent of inequality between rich and the poor."

In this paper, we analyse differences in cross-country incomes arising from the Penn World Table (Summers and Heston, 1991) and those based on prevailing exchange rates. Using the framework of the Balassa (1964)-Samuelson (1964) productivity-bias hypothesis, we investigate the implications of these income differences for (i) dividing up all countries in the world into two groups, the rich and the poor, and (ii) global income inequality. ${ }^{1}$ The key to this analysis is the income elasticity of the deviation of a country's exchange rate from its conventional purchasing power parity (PPP) value. We show that our estimate of this elasticity is in broad agreement with other results reported in the literature, once these are appropriately interpreted.

\section{Exchange Rates and Productivity}

The well-known Balassa-Samuelson model gives rise to strong links between international productivity differences and exchange rates, and leads to the prediction that rich (poor) countries' currencies tend to be over (under) valued. This model is set out in Figure 1 where we have a three-country world, a rich one (R), a poor one (P) and the rest of the world. In comparison to $\mathrm{P}, \mathrm{R}$ is more technologically advanced in the production of all goods, but

\footnotetext{
${ }^{1}$ For recent papers that discuss the links between globalisation, growth and inequality, see, e.g., Deaton (2003), Ravallion (2001, 20003), and Sala-i-Martin (2002).
} 
FIGURE 1

EXCHANGE RATES AND PRODUCTIVITY

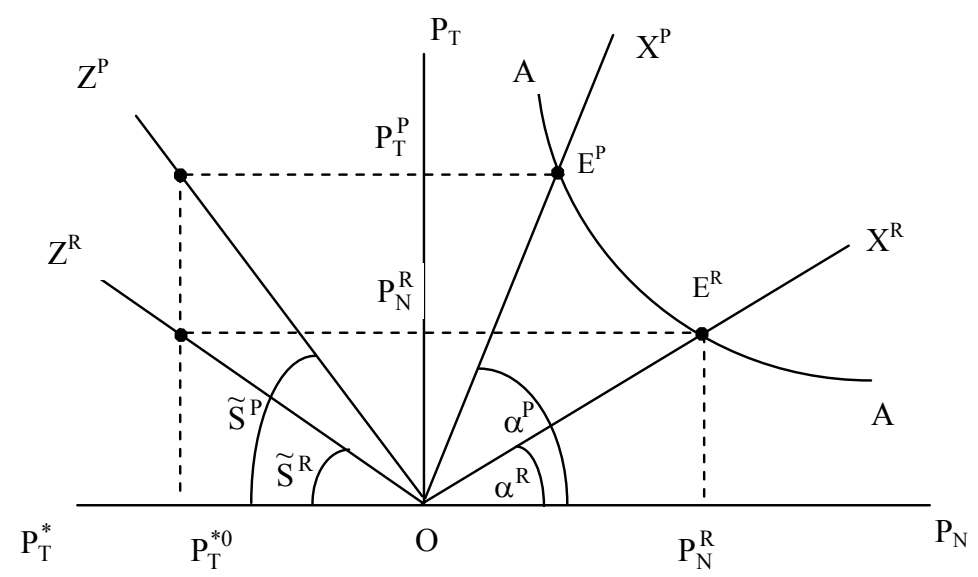

this advantage is amplified in the traded-goods sector. This leads to the relative price of traded goods in terms of nontraded $\mathrm{P}_{\mathrm{T}} / \mathrm{P}_{\mathrm{N}}$, to be denoted by $\alpha$, to be lower in $\mathrm{R}$, i.e., $\alpha^{R}<\alpha^{P}$. This is illustrated in the right-hand panel of Figure 1, where the slope of the ray from the origin $\mathrm{OX}$, the relative price schedule, is $\alpha$. The monetary side of the economy is summarised by the absolute price schedule AA in Figure 1. Points on AA represent combinations of the two nominal prices, $\mathrm{P}_{\mathrm{T}}$ and $\mathrm{P}_{\mathrm{N}}$, which yield a constant price level. To isolate the effects of differing relative price structures, both $\mathrm{R}$ and $\mathrm{P}$ share the same absolute price schedule, so that overall equilibrium is given by the points $\mathrm{E}^{\mathrm{R}}$ and $\mathrm{E}^{\mathrm{P}}$.

As the price level is taken to be the same in R and P, application of PPP to price levels (or "aggregative PPP") leads to the conclusion that their currencies should both have the same value in terms of a third currency. That is, if $S_{P P P}$ is the aggregative PPP exchange rate (the domestic currency cost of a unit of foreign exchange), then according to this version of PPP, $\mathrm{S}_{\mathrm{PPP}}=\mathrm{P} / \mathrm{P}^{*}$, where $\mathrm{P}$ and $\mathrm{P}^{*}$ are the price levels at home and abroad. Thus in the rich and poor countries, $\mathrm{S}_{\mathrm{PPP}}^{\mathrm{R}}=\mathrm{P}^{\mathrm{R}} / \mathrm{P}^{*}, \quad \mathrm{~S}_{\mathrm{PPP}}^{\mathrm{P}}=\mathrm{P}^{\mathrm{P}} / \mathrm{P}^{*}, \quad \mathrm{~S}_{\mathrm{PPP}}^{\mathrm{R}}=\mathrm{S}_{\mathrm{PPP}}^{\mathrm{P}} \quad$ as $\quad \mathrm{P}^{\mathrm{R}}=\mathrm{P}^{\mathrm{P}}$. Another version of PPP says that the exchange rate is the ratio of the price of traded goods at home to that abroad, $\widetilde{\mathrm{S}}=\mathrm{P}_{\mathrm{T}} / \mathrm{P}_{\mathrm{T}}^{*}$. In the left-hand panel of Figure 1 the ray from the origin $\mathrm{OZ}$ has slope $\widetilde{\mathrm{S}}$ and as can be seen, given the higher price of traded goods in the poor country, $\left(\mathrm{P}_{\mathrm{T}}^{\mathrm{P}}\right)$, its currency is worth less on the basis of this version of PPP. That is, $\widetilde{\mathrm{S}}^{\mathrm{P}}>\widetilde{\mathrm{S}}^{\mathrm{R}}$. 
If currencies are priced in a manner which is closer to traded goods PPP, rather than aggregative PPP, then foreign exchange costs more in the poor country than in the rich $\left(\widetilde{\mathrm{S}}^{\mathrm{P}}>\widetilde{\mathrm{S}}^{\mathrm{R}}\right)$. But as discussed above, if we use aggregative PPP, we would conclude that both currencies should be worth the same amount $\left(\mathrm{S}_{\mathrm{PPP}}^{\mathrm{P}}=\mathrm{S}_{\mathrm{PPP}}^{\mathrm{R}}\right)$, so that the rich (poor) country's currency is over (under) valued. This is the productivity-bias hypothesis.

\section{Cross-Country Incomes and the International Poverty Line}

Let $\tilde{Y}_{c}$ be GDP per capita for country c from the Penn World Table (PWT), expressed in terms of US dollars, and $Y_{c}^{\prime}$ be the country's GDP in terms of its domestic currency. Then as the PWT prices GDP to reflect both traded and nontraded goods prices, the

ratio $Y_{c}^{\prime} / \widetilde{Y}_{c}$ is the aggregative PPP exchange rate according to the PWT. As this $S_{P P P}$ is expressed in exactly the same way as the prevailing exchange rate $S_{c}$, we divide the former by the latter to define the exchange-rate discrepancy, $\mathrm{D}_{\mathrm{c}}$, as

$$
D_{c}=\frac{S_{P P P, c}}{S_{c}}=\frac{Y_{c}^{\prime}}{\widetilde{Y}_{c}} \times \frac{1}{S_{c}}=\frac{Y_{c}}{\widetilde{Y}_{c}}
$$

where $Y_{c}=Y_{c}^{\prime} / S_{c}$ is conventionally-defined GDP in US dollars. Columns 2 and 6 of Table 1 present $\tilde{Y}_{c}$ for $\mathrm{c}=1, \ldots, 77$ countries in 1992, ranked in descending order. Columns 3 and 7 give the corresponding $Y_{c}$ and columns 4 and 8 contain $D_{c}$. The discrepancies for rich countries are usually greater than one, while those for poor countries are less than one. The major exceptions to this rule are Hong Kong $\left(D_{c}=.8\right)$, Australia (.9) and New Zealand (.8). As a value of $\mathrm{D}>1(<1)$ means that the currency is over (under) valued, the behaviour of D with respect to income supports the productivity-bias hypothesis.

We now analyse the relationship between D and GDP by estimating

$$
\log D_{c}=\alpha+\beta \log \tilde{Y}_{c}+\varepsilon_{c}
$$

where $\alpha$ and $\beta$ are coefficients and $\varepsilon$ is a disturbance term. Using the data in Table 1, the least-squares estimates are $\hat{\alpha}=-4.06(.41)$ and $\hat{\beta}=.42(.05)$, where the figures in 
TABLE 1

TWO MEASURES OF GDP AND EXCHANGE RATES, 1992

\begin{tabular}{|c|c|c|c|c|c|c|c|}
\hline \multirow{3}{*}{$\begin{array}{c}\text { Country } \\
\text { (1) }\end{array}$} & \multicolumn{2}{|c|}{ GDP per capita (\$US) } & \multirow{3}{*}{$\begin{array}{l}\text { Exchange- } \\
\text { rate } \\
\text { discrepancy } \\
\text { (4) }\end{array}$} & \multirow{3}{*}{$\begin{array}{c}\text { Country } \\
\text { (5) }\end{array}$} & \multicolumn{2}{|c|}{ GDP per capita (\$US) } & \multirow{3}{*}{$\begin{array}{l}\text { Exchange- } \\
\text { rate } \\
\text { discrepancy } \\
\text { (8) }\end{array}$} \\
\hline & PWT & Conventional & & & & & \\
\hline & (2) & (3) & & & (6) & (7) & \\
\hline 1. Switzerland & 21,631 & 35,268 & 1.63 & 41. Algeria & 3,076 & 1,823 & .59 \\
\hline 2. Luxembourg & 21,144 & 33,151 & 1.57 & 42. Dominican Rep. & p. 2,918 & 1,205 & .41 \\
\hline 3. Hong Kong & 21,034 & 17,322 & .82 & 43. Guatemala & 2,888 & 1,072 & .37 \\
\hline 4. Canada & 20,970 & 21,052 & 1.00 & 44. Sri Lanka & 2,783 & 557 & .20 \\
\hline 5. Germany, West & 20,197 & 31,019 & 1.54 & 45. Morocco & 2,777 & 1,086 & .39 \\
\hline 6. Japan & 19,920 & 30,653 & 1.54 & 46. Paraguay & 2,655 & 1,427 & .54 \\
\hline 7. Denmark & 18,730 & 28,452 & 1.52 & 47. Peru & 2,620 & 1,613 & .62 \\
\hline 8. Australia & 18,500 & 17,475 & .94 & 48. Indonesia & 2,601 & 756 & .29 \\
\hline 9. Sweden & 18,387 & 28,526 & 1.55 & 49. Congo & 2,538 & 1,207 & .48 \\
\hline 10. France & 18,232 & 23,482 & 1.29 & 50. El Salvador & 2,274 & 1,090 & .48 \\
\hline 11. Belgium & 18,091 & 22,643 & 1.25 & 51. Egypt & 2,274 & 766 & .34 \\
\hline 12. Netherlands & 17,373 & 21,216 & 1.22 & 52. Philippines & 2,172 & 825 & .38 \\
\hline 13. Norway & 17,094 & 29,467 & 1.72 & 53. Romania & 2,130 & 1,083 & .51 \\
\hline 14. Austria & 16,989 & 23,747 & 1.40 & 54. Bolivia & 2,066 & 750 & .36 \\
\hline 15. Singapore & 16,736 & 17,418 & 1.04 & 55. Papua N.Guinea & a 1,972 & 1,079 & .55 \\
\hline 16. Italy & 16,724 & 21,308 & 1.27 & 56. Bangladesh & 1,908 & 275 & .14 \\
\hline 17. Iceland & 16,324 & 26,658 & 1.63 & 57. China & 1,838 & 349 & .19 \\
\hline 18. U.K. & 16,302 & 18,451 & 1.13 & 58. Pakistan & 1,793 & 409 & .23 \\
\hline 19. Finland & 15,619 & 21,540 & 1.38 & 59. Honduras & 1,792 & 615 & .34 \\
\hline 20. New Zealand & 15,502 & 11,771 & .76 & 60. India & 1,633 & 292 & .18 \\
\hline 21. Spain & 12,986 & 14,768 & 1.14 & 61. Zimbabwe & 1,479 & 650 & .44 \\
\hline 22. Israel & 12,783 & 12,851 & 1.01 & 62. Kenya & 1,176 & 320 & .27 \\
\hline 23. Ireland & 12,259 & 15,125 & 1.23 & 63. Nigeria & 1,132 & 351 & .31 \\
\hline 24. Cyprus & 11,742 & 9,614 & .82 & 64. Cameroon & 1,122 & 918 & .82 \\
\hline 25. Venezuela & 8,449 & 2,984 & .35 & 65. Mauritania & 1,083 & 534 & .49 \\
\hline 26. Mauritius & 8,025 & 2,902 & .36 & 66. Lesotho & 1,027 & 445 & .43 \\
\hline 27. Malaysia & 7,191 & 3,180 & .44 & 67. Rwanda & 961 & 275 & .29 \\
\hline 28. Uruguay & 6,736 & 4,109 & .61 & 68. Sierra Leone & 914 & 184 & .20 \\
\hline 29. Chile & 6,326 & 3,080 & .49 & 69. Mozambique & 898 & 126 & .14 \\
\hline 30. St.Kitts\&Nevis & 6,057 & 4,329 & .71 & 70. Madagascar & 757 & 242 & .32 \\
\hline 31. Hungary & 5,780 & 3,612 & .62 & 71. Burundi & 710 & 187 & .26 \\
\hline 32. Belize & 5,739 & 2,435 & .42 & 72. Togo & 669 & 430 & .64 \\
\hline 33. Fiji & 5,288 & 2,071 & .39 & 73. Uganda & 654 & 186 & .28 \\
\hline 34. Thailand & 5,018 & 1,922 & .38 & 74. Burkina Faso & 651 & 322 & .49 \\
\hline 35. Costa Rica & 4,522 & 2,659 & .59 & 75. Central Afr.R. & 634 & 445 & .70 \\
\hline 36. Colombia & 4,254 & 1,474 & .35 & 76. Malawi & 607 & 199 & .33 \\
\hline 37. Iran & 4,161 & 2,169 & .52 & 77. Chad & 504 & 279 & .55 \\
\hline 38. Panama & 4,102 & 2,641 & .64 & & & & \\
\hline 39. Tunisia & 3,807 & 1,842 & .48 & Mean & 7,346 & 7,801 & .69 \\
\hline \multirow[t]{3}{*}{ 40. Namibia } & 3,231 & 1,923 & .60 & Standard deviation & & & \\
\hline & & & & - levels & 7,136 & 10,540 & .44 \\
\hline & & & & $-\log _{s}(\times 100)$ & 116 & 171 & - \\
\hline
\end{tabular}

Source: The Penn World Table Version 5.6 (http://pwt.econ.upenn.edu/Downloads/pwt56old/pwt56.zip) and the IMF International Financial Statistics.

Note: The US is the numeraire country which according to the PWT has a GDP per capita of \$US23,220. 
parentheses are heteroscedesticity-adjusted standard errors. Thus the elasticity of D with respect to $\tilde{\mathrm{Y}}$ is .42 . This indicates that if the we go from one country to another which is 50 percent more affluent according to the PWT, the exchange-rate discrepancy increases by 21 percent. This is consistent with Samuelson's (1994, p. 201) assessment that "the greater [the per-capita income differentials of two countries] truly are, the greater tends to be the resulting coefficient of bias".

As $D_{c}>1 \quad(<1)$ for rich (poor) countries, it is thus natural to ask, what level of income divides countries into two groups, the rich and poor? That is, at what value of income, $\tilde{\mathrm{Y}}^{*}$, does $\mathrm{Y}=\tilde{\mathrm{Y}}$ hold, so that $\mathrm{S}_{\mathrm{PPP}}$ is equal to $\mathrm{S}$ and $\log \mathrm{D}=0$. It follows from equation (2) that $\tilde{\mathrm{Y}}^{*}=\exp (-\alpha / \beta)$. A simple way of evaluating this is to use the estimates from equation (2), so that $\tilde{\mathrm{Y}}^{*}=\exp (4.06 / .42)=\$ \mathrm{US16}, 260$ in 1992. This dividing level of income can be thought of as the "international poverty line" and is indicated in Figure 2. Table 1 shows that this poverty line lies between UK and Finland, and seems to be high compared to the mean over the 77 countries, \$US7,300. One may also question the classification of the majority of countries as "poor". Some additional qualifications to the

FIGURE 2

TWO MEASURES OF INCOME IN 77 COUNTRIES, 1992

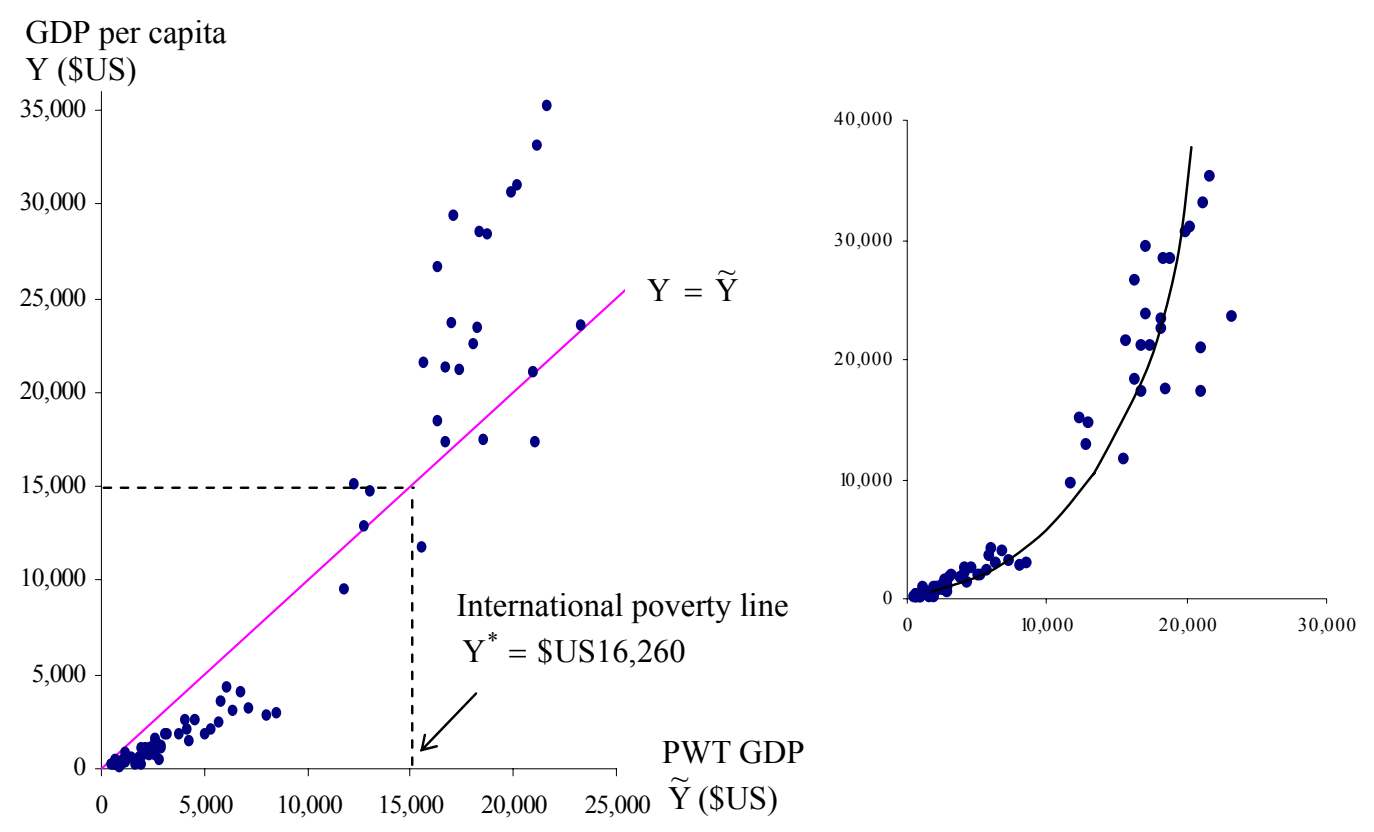


international poverty line are in order, of course. First, poverty is defined in an unconventional way, viz., on the basis of the relationship between the PPP exchange rate and the prevailing rate. This can be described as a "revealed preference" approach which uses the productivity-bias hypothesis as a maintained hypothesis.

A further qualification to the international poverty line is that as $\tilde{\mathrm{Y}}^{*}$ is defined as the ratio of two parameters and it is well known that when least-squares estimates are used to evaluate such ratios, there can be econometric problems due to certain moments not existing. Under normality of the disturbance term, the ratio of two least-squares estimates is not normally distributed and does not have finite moments (Bewley and Fiebig, 1990, Zellner, 1978). To overcome these problems, we use the nonparametric version of Efron's (1979) bootstrap simulation procedure. With 1,000 trials, we obtain the mean value of $\widetilde{\mathrm{Y}}^{*}$ of $\$ 16,539$, with a root-mean-square error (RMSE) of $\$ 3,040$. The mean value is not too far away from our point estimate of $\$ 16,260$. But the RMSE is sizeable, which serves as a warning that the international poverty line is not estimated too precisely.

The above discussion makes it clear that the international poverty line should not be interpreted literally. Rather, $\tilde{\mathrm{Y}}^{*}$ divides countries into two groups, those with high incomes and the rest.

\section{Global Inequality}

Figure 2 also contains a $45^{\circ}$ line from the origin corresponding to $\mathrm{Y}=\tilde{\mathrm{Y}}$. As can be seen, the low-income countries are all located below the $45^{\circ}$ line, while high-income counties are mostly above. This indicates that when incomes are converted into US dollars using prevailing exchange rates $\mathrm{S}$, poor countries' incomes tend to be underestimated, and rich countries' incomes tend to be overestimated. Accordingly, the "world" inequality of income is overstated by using S. This can also be seen from the last row in the right panel of Table 1 which gives the standard deviation of the logarithms of income. The PWT gives a standard deviation of 116 percent, while the conventional method produces 171 percent.

To further analyse inequality, we combine equations (1) and (2) to obtain 


$$
\log Y_{c}=\alpha+(1+\beta) \log \widetilde{Y}_{c}+\varepsilon_{c}
$$

which shows that the elasticity of $\mathrm{Y}$ with respect to $\widetilde{Y}$ is $1+\beta$; as $\hat{\beta}>0$, this elasticity exceeds unity. If $\sigma_{x}^{2}$ is the variance of $\log x$, and $\sigma_{\varepsilon}^{2}$ that of $\varepsilon$, equation (3) then implies that

$$
\sigma_{\mathrm{Y}}^{2}=(1+\beta)^{2} \sigma_{\widetilde{\mathrm{Y}}}^{2}+\sigma_{\varepsilon}^{2}
$$

If $\sigma_{\varepsilon}^{2}<<\sigma_{\widetilde{Y}}^{2}$, it follows from equation (4) that $\sigma_{\mathrm{Y}} / \sigma_{\widetilde{Y}} \approx 1+\beta$. From equation (2), we obtain the least-squares estimate of $\sigma_{\varepsilon}^{2}, \hat{\sigma}_{\varepsilon}^{2}$, to be .17 . As $\hat{\beta}=.42$ and $\sigma_{\widetilde{Y}}=1.16$ (from the last row of Table 1), we derive (i) from equation (4) that $\sigma_{\mathrm{Y}}=1.70$, which agrees rather well (as it should) with the observed dispersion of $\mathrm{Y}$ of 1.71, given in the last row of Table 1; and (ii) $\sigma_{\mathrm{Y}} / \sigma_{\widetilde{Y}}=1.70 / 1.16=1.47$, which is not too different to the estimated value of $1+\beta$, viz., 1.42. This illustrates a type of "magnification effect" of using prevailing exchange rates to convert incomes into a common currency -- using prevailing exchange rates has the effect of magnifying the cross-country inequality of income by about 50 percent.

To provide some further insight into the magnification effect, the right-hand side of Figure 2 gives the same scatter plot as on the left but on a smaller scale. Added to the scatter is a sketch of a curve that more or less passes through the centre of gravity of the data. This curve is positively sloped with an increasing slope. One functional form that matches these properties is $\mathrm{Y}=\mathrm{a} \tilde{\mathrm{Y}}^{\mathrm{b}}$, where $\mathrm{a}$ and $\mathrm{b}$ are constants, with $\mathrm{a}>0$ and $\mathrm{b}$ being the elasticity of $\mathrm{Y}$ with respect to $\tilde{\mathrm{Y}}$. The slope takes the form $\mathrm{ab} \widetilde{\mathrm{Y}}^{\mathrm{b}-1}$ and the change in the slope is $a b(b-1) \tilde{Y}^{b-2}$; a positive slope requires that $b>0$ and the increasing slope establishes that $b>1$. Note also that as $b$ is the elasticity, it is equal to the slope of the curve (the marginal effect, $a b \widetilde{Y}^{b-1}=b Y / \widetilde{Y}$ ) divided by the slope of the corresponding ray from the origin (the average, $\mathrm{Y} / \tilde{\mathrm{Y}}$ ). Accordingly, $\mathrm{b}>1$ as the marginal effect is always greater than the average. The coefficient $b$ is $1+\beta$ in equation (3), and as indicated above $1+\beta>0$ is the source of the magnification effect. 


\section{Comparison with Previous Studies}

In the above discussion of the international poverty line and income inequality, the value of the elasticity $\beta$ in equation (2) is of key importance. In this section we show that our estimate of $\beta$ of .42 is not inconsistent with prior studies.

Equation (2) gives the relationship between the exchange-rate discrepancy $\mathrm{D}$ and the PWT GDP, $\tilde{Y}$. Combining equations (2) and (3), we can express D in terms of $\mathrm{Y}$ as

$$
\log D_{c}=\alpha^{\prime}+\beta^{\prime} \log Y_{c}+\varepsilon_{c}^{\prime}
$$

where $\beta^{\prime}=\beta /(1+\beta), \quad \alpha^{\prime}=\alpha\left(1-\beta^{\prime}\right), \varepsilon^{\prime}=\varepsilon\left(1-\beta^{\prime}\right)$ are new slope coefficient, intercept and disturbance term, respectively. Using $\hat{\beta}=.42$, the elasticity of $\mathrm{D}$ with respect to $\mathrm{Y}$ is $\hat{\beta}^{\prime}=.42 /(1+.42)=.30$. Balassa (1964) regresses $\mathrm{D}$ (expressed as a percentage) on GNP per capita in US dollars and obtains $\mathrm{D}=49.34+.025 \mathrm{Y}$. At sample means (denoted by a bar), the implied elasticity of $\mathrm{D}$ with respect to $\mathrm{Y}$ is $[\mathrm{d} \mathrm{D} / \mathrm{d} \mathrm{Y}] \times(\overline{\mathrm{Y}} / \overline{\mathrm{D}})=.025 \times 1200 / 80=.38$, which is not too different from our estimate of .30 .

Let us choose units such that prices in the rest of the world are all unity and suppose that (i) the aggregative PPP exchange rate is proportional to a weighted geometric mean of $\mathrm{P}_{\mathrm{T}}$ and $\mathrm{P}_{\mathrm{N}}, \mathrm{S}_{\mathrm{PPP}}=\eta_{1} \mathrm{P}_{\mathrm{T}}^{\gamma} \mathrm{P}_{\mathrm{N}}^{1-\gamma}$, where $\eta_{1}$ is a positive constant and $\gamma$ is the weight assigned to traded goods; and (ii) the prevailing exchange rate is proportional to $\mathrm{P}_{\mathrm{T}}: \mathrm{S}=\eta_{2} \mathrm{P}_{\mathrm{T}}$, where $\eta_{2}$ is another positive constant. The discrepancy is then $\mathrm{D}=\mathrm{S}_{\mathrm{PPP}} / \mathrm{S}=\eta_{1} \mathrm{P}_{\mathrm{T}}^{\gamma} \mathrm{P}_{\mathrm{N}}^{1-\gamma} / \eta_{2} \mathrm{P}_{\mathrm{T}}$, or

$$
\log \mathrm{D}=\eta+(1-\gamma) \log \frac{\mathrm{P}_{\mathrm{N}}}{\mathrm{P}_{\mathrm{T}}}
$$

where $\eta=\log \left(\eta_{1} / \eta_{2}\right)$. Combining equations (5) and (6) and ignoring the country subscripts and disturbance term, we have

$$
\log \frac{\mathrm{P}_{\mathrm{N}}}{\mathrm{P}_{\mathrm{T}}}=\delta+\frac{\beta^{\prime}}{1-\gamma} \log \mathrm{Y}
$$


where $\delta$ is a constant. Clements and Semudram (1983) examine the cross-country relationship between the price of haircuts and GDP per capita. The price in domesticcurrency terms is $\mathrm{P}_{\mathrm{H}}$, which is then converted to US dollars using the prevailing exchange rate, to yield $\mathrm{P}_{\mathrm{H}} / \mathrm{S}$. As haircuts are highly labour intensive, they themselves can be considered to be a nontraded good par excellent, so that $\mathrm{P}_{\mathrm{H}} / \mathrm{S}$ can be interpreted as the relative price of nontraded goods $\mathrm{P}_{\mathrm{N}} / \mathrm{P}_{\mathrm{T}}$. Clements and Semudram find that the elasticity of $\mathrm{P}_{\mathrm{H}} / \mathrm{S}$ with respect to $\mathrm{Y}$ is .26 . From equation (7), the elasticity of $\mathrm{P}_{\mathrm{N}} / \mathrm{P}_{\mathrm{T}}$ with respect to $\mathrm{Y}$ is $\lambda=\beta^{\prime} /(1-\gamma)=.30 /(1-\gamma)$ for $\hat{\beta}=.42$. As $0<\gamma<1$, the above elasticity exceeds .3 . But if we interpret $\gamma$ as the share of traded goods in the overall economy, this terms falls as income rises and/or the overall size of the economy grows. Thus for more affluent and larger countries, we would not expect $\lambda$ to be substantially above .3 . This bound on the value of $\lambda$ is not too different from the Clements and Semudram's estimate of this elasticity of .26.

Finally, Heston et al. (1994) regress the logarithm of the ratio of (adjusted) tradable to non-tradable goods prices on GDP per capita. They estimate that the elasticity of $\mathrm{P}_{\mathrm{T}} / \mathrm{P}_{\mathrm{N}}$ with respect to $\mathrm{Y}$ for the years 1970, 1975, 1980, 1985 ranges from -.16 to -.28. This elasticity is just the negative of the elasticity in equation (7). The estimated range in Heston et al. is not inconsistent with our findings.

\section{Concluding Comments}

It is well known that the currencies of rich countries trend to be overvalued on a conventional PPP basis, and vice versa for poor countries. We used this relationship to introduce the "international poverty line", the value of income which divides all countries in the world into two groups, the rich and the poor, on the basis of the divergence of their exchange rates from PPP. We then explored the implications for the measurement of global income inequality, and showed that using prevailing exchange rates has the effect of magnifying cross-country inequality by about 50 percent. Finally, we showed that our results are not inconsistent with those reported in the previous literature when appropriately interpreted. 


\section{$\underline{\text { References }}$}

Bewley, R. and D. G. Fiebig (1990). "Why are Long-Run Parameter Estimates so Disparate?" Review of Economics and Statistics 72: 345-9.

Balassa, B. (1964). “The Purchasing-Power Parity Doctrine: A Reappraisal.” Journal of Political Economy 72: 58496.

Clements and M. Semudram (1983). "An International Comparison of the Price of Nontraded Goods." Weltwirtschaftliches Archiv 119: 356-63.

Deaton, A. (2003). "Measuring Poverty in A Growing World (or Measuring Growth in a Poor World)." NBER Working Paper 9822.

Efron, B. (1979). "Bootstrap methods: Another Look at the Jackknife." The Annals of Statistics: 1-2

Heston, A., D. A. Nuxoll and R. Summers (1994). “The Differential-Productivity Hypothesis and Purchasing-Power Parities: Some New Evidence." Review of International Economics 2: 227-43.

Ravallion, M. (2001). "Growth, Inequality and Poverty: Looking beyond the Averages." World Development 29: 1803-15.

Ravallion, M. (2003). Measuring Aggregate Welfare in Developing Countries: How Well do National Accounts and Surveys Agree?" Review of Economics and Statistics 85: 645-52.

Sala-i-Martin, X. (2002). “The Disturbing 'Rise' of Global Income Inequality.” NBER Working Paper 8904.

Samuelson, P. A. (1964). "Theoretical Notes on Trade Problems.” Review of Economics and Statistics 46: 145-54.

Samuelson, P. A. (1994). "Facets of Balassa-Samuelson Thirty Years Later." Review of International Economics 2: 201-26.

Summers, R. and A. Heston (1991). "The Penn World Table (Mark 5): An Expanded Set of International Comparisons, 1950-1988." Quarterly Journal of Economics 106: 327-68.

Zellner, A. (1978). "Estimation of Functions of Population Means and Regression Coefficients including Structural Coefficients: A Minimum Expected Loss (MELO) Approach.” Journal of Econometrics 8: 127-58. 